\title{
Yabancı Dil Olarak Türkçe Öğretiminde Elektronik Dinletilerin Dinlediğini Anlama Başarısı ve Dinleme Kaygısına Etkisi*
}

\author{
Rifat Ramazan Berk **, Fatma Açı*** \\ Makale Geliş Tarihi: 07/06/2020 \\ Makale Kabul Tarihi: 04/08/2020
}

DOI: $10.35675 /$ befdergi.747319

$\ddot{O} z$

Elektronik dinletiler dil ögrretiminde/öğreniminde taşınabilir ve esnek dil öğretim materyalleri sunması açısından yenilikçi bir teknoloji olarak kabul edilmektedir. Çalışmada edinletilerin yabancı dil olarak Türkçe öğrenenlerin dinlediğini anlama başarısı ve dinleme kaygısına etkisi incelenmektedir. Araştırmanın çalışma grubunu Afganistan'da yabancı dil olarak Türkçe öğrenen B2 düzeyindeki 61 öğrenci oluşturmaktadır. Çalışmada nicel araştırma yöntemlerinden yarı-deneysel desen kullanılmıştır. Deney grubundaki ögrencilere altı hafta süreyle haftada bir kez dil öğrenimlerini destekleyici e-dinleti gönderilmiştir. Kontrol grubundaki ögrrenciler ise geleneksel yöntemlerle dinleme derslerine devam etmiştir. Veri toplama aracı olarak Türkçe Yeterlik Sinavının dinleme bölümü, "Yabancı Dilde Dinleme Kaygısı Ölçeği" ve "Katılımcı Tanıma Formu” kullanılmıştır. Araştırmadan elde edilen bulgular neticesinde dinlediğini anlama başarısı açısından deney grubundaki öğrencilerin kontrol grubundaki ögrencilerden daha başarılı olduğu tespit edilmiştir. Deney grubundaki ögrencilerin kaygı düzeylerinin kontrol grubundaki ögrencilerden istatistiksel açıdan anlamlı düzeyde daha düşük olduğu tespit edilmiştir. Çalışmanın sonuçları, e-dinletilerin yabancı dil olarak Türkçe öğretiminde kullanılabilecek etkili bir araç olduğunu ortaya koymaktadır.

Anahtar Kelimeler: Dinlediğini anlama başarısı, dinleme kaygısı, e- dinleti, podcast, yabancılara Türkçe öğretimi

* Bu çalışma birinci yazarın ikinci yazar danışmanlığında hazırladığı "Yabancı dil olarak Türkçe öğretiminde elektronik dinletilerin dinlediğini anlama başarısı ve dinleme kaygısına etkisi” başlıklı doktora tezinden hazırlanmıştır.

**Bayburt Üniversitesi, Türkçe Öğretimi Uygulama ve Araştırma Merkezi, Bayburt, Türkiye, rifatberk@bayburt.edu.tr, ORCID: 0000-0002-7505-7787

***Gazi Üniversitesi, Gazi Eğitim Fakültesi, Türkçe ve Sosyal Bilimler Eğitimi Bölümü, Türkçe Eğitimi Anabilim Dalı, Ankara, Türkiye, fatmaacik1 @ gazi.edu.tr, ORCID: 0000-00023972-0799

Kaynak Gösterme: Berk, R.R., \& Açık, F. (2021). Yabancı dil olarak Türkçe öğretiminde elektronik dinletilerin dinlediğini anlama başarısı ve dinleme kaygısına etkisi. Bayburt Eğitim Fakültesi Dergisi, 16(32), 329-348. 


\title{
The Effects of Podcasts on Listening Comprehension and Listening Anxiety in Teaching Turkish as a Foreign Language
}

\begin{abstract}
Podcasting is an innovative technology in language learning. In this study, the effect of podcasts on listening comprehension and listening anxiety of students who learn Turkish as a foreign language are examined. The sample consists of 61 students at the B2 level who learn Turkish as a foreign language in Afghanistan. Supplementary podcasts were sent to the experimental group once a week for six weeks. The students in the control group continiued their lessons with traditional methods. "Turkish Proficiency Test, "Foreign Language Listening Anxiety Scale", "Participant Identification Form” were used as data collection tools. Findings revealed that there is a significant difference of listening comprehension post-test score between two groups, favoring experimental group. The anxiety levels of students in the experimental group were significantly lower than control group. The results of the study reveal that podcasts are an effective tool for teaching Turkish as a foreign language.
\end{abstract}

Keywords: Listening anxiety, listening comprehension, podcast, teaching Turkish as a foreign language.

\section{Giriş}

Türkçenin yabancılara öğretiminde nihaî amaç dört temel dil becerisinin geliştirilmesidir. Öğrencilerin okuduğunu ve dinlediğini doğru anlamaları; duygu, düşünce ve hayallerini açık ve anlaşılır biçimde yazılı ve sözlü ifade edebilme becerisi kazanabilmeleri için hedef kitlenin dinleme, okuma, konuşma ve yazma becerilerini geliştirmeleri beklenmektedir.

Yabancı dil olarak Türkçe öğretiminde, hedef kitlede geliştirilmesi gereken ilk beceri okuma, yazma ve konuşma becerilerinin temelini oluşturduğundan dinleme becerisidir (Güneş, 2007, s. 73). Konuşmacının ileri sürdüğü düşünceleri anlamak, yorumlamak, değerlendirmek, organize etmek, aralarındaki ilişkileri saptamak dinleme becerisiyle sağlanmaktadır (Taşer, 2000, s. 214). Dinleme becerisi aynı zamanda hedef dilin girdilerini anlamada ve karşılıklı iletişimin gerçekleşmesinde kilit rol oynamaktadır.

Dinleme becerisinin ana dil edinimi ve ikinci/yabancı dil öğretimindeki öneminin bilinmesine rağmen dil öğretimi alanında gerek araştırmacılar gerekse uygulayıcılar tarafından ihmal edilen bir beceri olduğu bilinen bir gerçektir (Dilidüzgün, 2013, s. 259; Nation \& Newton, 2008, s. 37; Tabak \& Göçer, 2014). Hatta dinleme becerisi diğer dil becerilerine kıyasla üzerinde en az durulan, anlaşılan ve araştırma yapılan dil becerisidir (Field, 2013; Vandergrift, 2007).

Açık (2008) tarafından yabancı dil olarak Türkçe öğrenen öğrencilerin sorunlarını tespit etmek amacıyla yapılan araştırmada, Gazi ve Ege Üniversitelerine bağlı 
TÖMER'lerden rastgele seçilen 100 öğrencinin $\quad \% \quad 17^{\prime}$ 'sinin anlamada (dinleme/anlama) problem yaşadıkları ifade edilmektedir. Maden ve İşcan (2011) tarafından, Hindistan'da yabancı dil olarak Türkçe öğrenen öğrencilerin yaşadıkları sorunları belirlemek amacıyla yapılan çalışmada, 116 öğrenciden 11'inin dinlemede sorun yaşadı̆̆ ifade edilmektedir. Aynı çalışmada öğrencilere yöneltilen "Türkçeyi dinleyip anlayabiliyor musunuz?" sorusuna \% 37,9'unun "Hayır", \% 35,34'ünün ise "Biraz" şeklinde cevap verdikleri belirtilmiştir. Kaldırım ve Degeç (2017) sekiz TÖMER öğrencisinin dinleme esnasında karşılaştıkları sorunları belirlemeye yönelik bir araştırma yapmıştır. Araştırmaya göre öğrencilerin dinleme esnasında birçok sorunla karşılaştığı görülmüştür. Bu sorunların konuşmacıdan ve konuşma dilinin özelliklerinden kaynaklandığı gibi dinleyici özelliklerinden de kaynaklandığı belirtilmiştir. Büyükikiz (2014) ise C1 düzeyindeki öğrencilerin dinleme becerisine ilişkin görüşlerini incelemiştir. Çalışmaya göre öğrenciler Türkçe öğreniminde dinlemeyi zor bulmaktadır. Öğrenciler Türkçe dinlerken bazı sesleri anlayamadıklarını; bazı kelimelerin birden fazla anlamda kullanılmasının ve mecazlı söylemlerin dinlemeyi zorlaştırdığını ifade etmişlerdir. Dolayısıyla ülkemizde yapılan sınırlı sayıdaki araştırma sonuçları incelendiğinde öğrencilerin dinleme becerisini geliştirmede birçok zorlukla karşılaştığı görülmektedir.

Yapılan araştırmalar (Bingöl, Çelik, Yıldız \& Mart, 2014; Carroll, 1977; Hamouda, 2013; Underwood, 1989) dinleme becerisinin öğretiminde telaffuz, konuşma hızı, yetersiz söz dağarcı̆̆ı, konuşmacıların farklı aksanları, konsantrasyon eksikliği, söylem belirleyicilerin eksikliği, bağlamsal bilgideki eksiklikler, sınıf içi fiziksel yetersizlikler, dinletilen ses kayttlarının uzunluğu ve kalitesi, kültürel farklılıklar ve kaygıyla ilgili sorunlar yaşandığını göstermektedir.

Dilidüzgün'e (2013, s. 259) göre, yazılı dilden farklı özellikler taşıyan günlük bir konuşmada normal hızda olsa bile eksiltili cümlelerle, söylem belirleyicilerle dolu yanıtları anlamak güçtür. Bu tür durumlarda karşıdaki konuşmacıyı sadece anlamak değil aynı zamanda söylediklerine uygun cevaplar vermek zorunda olan dinleyici için kaygı ve stresin yükselmesi olasıdır (Vandergrift \& Goh, 2012, s. 4). Karşı1ıklı konuşmalarda, okumada olduğu gibi tekrar şansının olmaması; metni yavaşlatma veya parçalara bölerek anlamaya çalışma gibi seçeneklerin bulunmaması dinleyicilerin kaygı̈ düzeylerini arttırmaktadır.

Polat ve Erişti (2018), yabancı dilde dinleme kaygısını "yabancı bir dili öğrenmekte olan ya da öğrendiklerini kullanan bireylerin dinleme süreci öncesinde ve süreç boyunca yaşadıkları, becerinin yerine getirilme biçiminin gerekli kıldığ 1 eylemler ve farklı uyaranlardan kaynaklanan huzursuzluk, endişe, gerginlik, tedirginlik, korku duyguları" şeklinde tanımlanmaktadır. Altunkaya (2017) ise "bireyin iletişim sürecinde dinlediklerini anlamlandıramama tehdidi altında kendisini huzursuz, gergin, endişeli hissetmesi ve bu hislere bağlı olarak kalp atım hızında değişiklik, kızarma, terleme gibi fiziksel tepkiler hissetmesi” şeklinde tanımlamaktadır. Araştırmacıya göre, öğrencilerin aşina olmadıkları sesleri, 
kelimeleri, cümleleri işitip kavramak ve yorumlamak zorunda olmaları dinleme kaygısının nedenleri olarak görülmektedir. Lund (1991) ve Young (1992) ise dinleme metniyle ilgili görevlerin öğrencinin dinleme kaygısını yükselttiğini ifade etmektedir. Krashen (1982) de girdinin anlaşılabilir olmadığı durumlarda dinleme kaygısının artarak duyuşsal filtre oluşturduğunu iddia etmektedir.

Scarcella ve Oxford (1992), sınıf içi dinleme görevlerinin çok zor olduğu ya da öğrencilerin alışık olmadığı görevlerle karşılaştıklarında dinleme kaygılarının arttığını ifade etmektedir. Başka bir çalışmasında ise Oxford (1993) kaygının nedenini öğrenme hedefleri ve öğrenenlerin inançları olarak açıklamaktadır. Oxford'a göre hedef dildeki dinleme etkinlikleri öğrencilerde başarısızlık hissine yol açmaktadır. Öğrenciler ana dillerinde bile dinledikleri her metni kelimesi kelimesine anlamaya çalışmadıkları halde hedef dildeki dinleme metinlerinde geçen bütün kelimeleri anlamaya çalışmaktadır. Bu durum öğrencilerde kaygı düzeyinin artmasına neden olurken ana dildeki dinleme becerilerini ikinci dilde dinleme etkinliklerine transfer etmelerinde engel oluşturmaktadır.

Türkçenin yabancı dil olarak öğretiminde öğrencilerin farklı ülkelerden Türkiye'ye gelerek Türkçe öğrendiğini düşündüğümüzde sınıf içi eğitim-öğretim etkinliklerine ek olarak günlük yaşantılarında konuşma diline maruz kalabilecekleri ve hedef dille ilgili girdilerini artırabilecekleri düşünülebilir. Candaş Karababa (2009) da Türkçeyi yurt dışında öğrenenlerle, Türkiye'de çok kültürlü sınıf ortamlarında öğrenenler olmak üzere hedef kitleyi ikiye ayırmakta ve Türkçeyi yurt dışında öğrenenlerle Türkiye'de öğrenenlerin gereksinimlerinin farklı olduğunu ifade etmektedir. Türkçeyi ülkemizde yabancı dil kapsamında öğrenenler dille birlikte kültürü de öğrenebilirler. Yurt dışında öğrenenlerse kültür, çevresel etkiler ve günlük yaşama dâhil olma gibi dil öğrenimini destekleyen bazı faktörlerden mahrumdurlar. Türkçeyi yurt dışında öğrenen kişilerin sınıf-içi etkinlikler, dersin öğretmeni ve ders kitaplarındaki dinleme metinlerinin dişında dile (seviyelerine uygun) maruz kalabilme ihtimalleri oldukça düşüktür. Dolayısıyla Türkçeyi yabanc1/ikinci dil olarak öğrenenler için geliştirilecek materyaller, Türkçeyi yurt dışında öğrenen yabancı uyruklu kişiler de düşünülerek tasarlanmalı, dinleme becerisine yönelik etkinlikler dil seviyelerine uygun bir şekilde zenginleștirilerek, hedef kitlenin dile maruz kalma oranı artırılmalıdır. Nitekim Graham ve Santos (2015, s. 10), ikinci/yabancı dil öğretiminde dinleme eğitiminin önemli noktalarından bahsederken etkili bir dinleme eğitiminin yoğun bir dinleme gerektirdiğini ifade etmektedir.

Geleneksel olarak tebeşir ve kalemle ders anlatımının akıllı tahtalar ve başka teknolojik gelişmelere paralel olarak terk edilmeye başlandığı; ikinci/yabancı dil öğretiminde iletişimsel yaklaşımın geniş anlamda kabul gördüğü ve görsel/işitsel materyallerin ön plana çıkmaya başladığı bir gerçektir. Bu durumda, özellikle bilgisayar teknolojisi veya mobil teknolojiler kullanılarak hazırlanmış materyallere yabancılara Türkçe öğretimi süreçlerinde ihtiyaç duyulduğu söylenebilir. Bu anlamda, 
“Mobil Destekli Dil Öğrenimi”nin Türkçenin yabancı dil olarak öğrenimi/öğretimi ortamlarında etkin bir şekilde kullanılması gerekmektedir.

Mobil öğrenme yaygın olarak internet bağlantısı özelliği olan taşınabilir cihazların eğitim amaçlı kullanımı olarak tanımlanmaktadır (Wang, Wiesemes \& Gibbons, 2012). Mobil destekli dil öğrenimi, dil öğrenmede -özellikle de kullanılan araçların taşınabilirliğinin özel avantajlar sunduğu durumlarda mobil teknolojilerin kullanılmasıdır. Mobil öğrenme sistemlerine erişimde en çok kullanılan araçlar ise cep telefonları, kişisel cep bilgisayarları, akıllı telefonlar, tablet bilgisayarlar, taşınabilir medya oynatıcıları, taşınabilir oyun konsolları şeklinde sıralanmaktadır (Merchant, 2012).

Son yıllarda mobil cihazların gelişimiyle uzaktan eğitim yayılmış ve bu cihazlar yaşam boyu öğrenmeyi desteklemeye başlamıştır. Bu uygulamalar arasında internetten bilgisayara ya da cep telefonlarına indirilebilen mp3 formatındaki ses dosyaları olarak tanımlanan e-dinletiler (podcastler) (McBride, 2009) Türkiye dışında Türkçe öğrenen kişilerin dinleme becerilerini geliştirmede kullanılabilecek bir araç olarak eğitim ortamlarında aktif bir şekilde kullanılabilir.

Birçok araştırmacı farklı e-dinleti türlerinin (McCombs \& Liu, 2007; McGarr, 2009) dilin farklı boyutlarına (Abdous, Camarena \& Facer, 2009; Chan, Chen \& Dopel, 2011; Chan, Chi, Chin \& Lin, 2011; Chester, Buntine, Hammond \& Atkinson, 2011; Lazzari, 2009; O’Bryan \& Hegelheimer, 2007) etkisini incelemiştir. Bu çalışmalarda kullanılan e-dinleti türleri sadece seslerden oluşan, sesin yanı sıra resimlerle genişletilmiş ve video e-dinletiler olmak üzere üç çeşittir. McGarr (2009) ise e-dinletilerin akademik ortamlarda destekleyici, ders yerine kullanılan ve yaratıcı e-dinletiler olmak üzere üç farklı şekilde kullanılabileceğini ifade etmektedir. Destekleyici e-dinletiler öğrencilerin anlama becerisini geliştirebilmek için tamamlayıcı materyaller sunmaktadır. Derslerin yerine kullanılan e-dinletiler ise sınıfta anlatılan dersin kaydını içermekte ve öğrenci derste kaçırdığı ya da anlamadığı konuları gözden geçirmek istediğinde bu e-dinletileri kullanmaktadır. Yaratıcı edinletiler ise öğrencilerin kendileri tarafından geliştirilen e-dinletilerdir.

Öğrencilerin hedef dile yönelik motivasyonlarının yükselebilmesi, hedef dili işlevsel bir şekilde kullanabilmeleri için anlamlı girdileri ve hedef dilin kültürüne ait bilgilerini artırmaları gerekmektedir. Royal ve Von Koss'a (2008) göre e-dinletiler dil öğretiminde bu amaçların gerçekleşmesini sağlayabilecektir. E-dinletilerin öğrenmeye sağladığı faydalar 2005 yılından itibaren birçok araştırmacı tarafından dile getirilmiştir (Clark \& Walsh, 2005; Kaplan Leiserson, 2005; Meng, 2005; Sloan, 2005; Stanley, 2006). E-dinletiler taşınabilir, kullanımı ve erişimi kolay materyaller sunmaktadır (Blaisdell, 2006). Kullanıcılar istedikleri yerde ve zamanda e-dinletilere erişebildikleri gibi "durdur" özelliği sayesinde istedikleri hızda bilgiye erişebilmektedir. Durdurma, ileri alma, geri alma, tekrar tekrar dinleme gibi seçenekleri kullanıcıların kontrolündedir (Sloan, 2005). Bu durum, özel ihtiyacı olan öğrencilere veya öğrenme seçeneklerine destek sağlamaktadır. Aynı zamanda e- 
dinletiler materyaller üzerindeki fiziksel bağımlılığı azaltmaktadır (Menzies, 2005). Bunların yanı sıra taşınabilir medya oynatıcılarına sahip olmayan öğrencilerin de edinleti içeriklerine bilgisayarla, tabletle vb. erişilebilmesi e-dinletilerin diğer bir avantajı olarak görülebilir.

Nitekim alan yazındaki çalışmalar incelendiğinde e-dinletilerin dinlediğini anlama başarısına olumlu etki ettiğini belirten birçok çalışma görülmektedir (Abdulrahman, Basalama \& Widodo, 2018; Al Fadda \& Al Qasim, 2013; NamazianDost, Bohloulzadeh \& Rahmatollahi, 2017; Rahimi \& Soleymani, 2015; Shiri, 2015). Türkçenin yabancı dil olarak öğretimi alanında e-dinletilerle ilgili sadece bir çalışmaya ulaşılabilmiştir. Yılmaz ve Babacan (2015), çalışmalarında yabancı dil olarak Türkçe öğretiminde dinleme becerisini geliştirmeye yönelik e-dinletiler geliştirmişlerdir. Çalışmada Avrupa Dilleri Ortak Çerçeve Metninde yer alan konu sınıflandırmaları doğrultusunda Türkçe öğretim materyalleri geliştirmişlerdir. Belirlenen temalar çerçevesinde belli hedef ve kazanımlar gözetilerek A1 ve A2 seviyelerinde altı e-dinleti tasarlanmıştır. Alan yazınımızda e-dinletilerin Türkçenin yabancı dil olarak öğretiminde dil becerilerine etkisini inceleyen herhangi bir çalışma henüz mevcut değildir.

$\mathrm{Bu}$ çalışmada, e-dinletilerle desteklenen dil öğretiminin, Türkçeyi yabancı dil olarak öğrenen B2 seviye öğrencilerin dinlediğini anlama başarısına ve dinleme kaygısına etkisinin belirlenmesi amaçlanmaktadır. Bu amaç doğrultusunda aşağıdaki sorulara cevap aranmaktadir:

1. E-dinletilerle desteklenen dil öğretiminin uygulandığı deney grubunun dinlediğini anlama başarısı ve dinleme kaygısı açısından ön test ve son test puanları arasında istatistiksel olarak anlamlı bir farklılık var mıdır?

2. Geleneksel yöntemle dil öğretiminin uygulandığı kontrol grubunun dinlediğini anlama başarısı ve dinleme kaygısı açısından ön test ve son test puanları arasında istatistiksel olarak anlamlı bir farklılık var mıdır?

3. E-dinletilerle desteklenen dil öğretiminin uygulandığı deney grubu ve geleneksel yöntemle dil öğretimine devam eden kontrol grubunda dinlediğini anlama başarısı ve dinleme kaygısı son test puanları arasında anlamlı bir farklılık var midir?

\section{Yöntem}

\section{Araştırmanın Modeli}

E-dinletilerin yabancı dil olarak Türkçe öğrenen öğrencilerin dinlediğini anlama başarılarına ve yabancı dilde dinleme kaygılarına etkisinin incelendiği bu çalışmada nicel araştırma yöntemlerinden ön test - son test kontrol gruplu yarı-deneysel araştırma deseni kullanılmıştır. Yarı-deneysel araştırma yöntemi deney ve kontrol gruplarına rastgele atama olmaksızın bağımsız değişkene müdahalede bulunup bu 
durumun bağımlı değişken üzerindeki etkisinin araştırıldığı bir yöntemdir. Rastgele atamanın yapılmadığı durumlarda tam deneysel desene alternatif olarak kullanıldığı bir yöntem olarak açıklanabilir (McMillan \& Schumacher, 2010).

Tablo 1.

Çalışmada Kullanılan Araştırma Modeli

\begin{tabular}{|c|c|c|c|}
\hline Gruplar & Ön Test & Müdahale & Son Test \\
\hline $\begin{array}{l}\text { Deney } \\
\text { Grubu }\end{array}$ & $\begin{array}{c}\text { Başarı Testi } \\
\text { Yabancı Dilde Dinleme Kaygısı } \\
\text { Ölçeği } \\
\text { Katılımcı Tanıma Formu }\end{array}$ & $\begin{array}{l}\text { Destekleyici E- } \\
\text { Dinleti } \\
\text { Uygulamaları }\end{array}$ & $\begin{array}{c}\text { Başarı Testi } \\
\text { Yabancı Dilde Dinleme } \\
\text { Kaygısı Ölçeği }\end{array}$ \\
\hline $\begin{array}{l}\text { Kontrol } \\
\text { Grubu }\end{array}$ & $\begin{array}{c}\text { Başarı Testi } \\
\text { Yabancı Dilde Dinleme Kaygısı } \\
\text { Ölçeği } \\
\text { Katılımcı Tanıma Formu }\end{array}$ & $\begin{array}{c}\text { Geleneksel } \\
\text { Etkinlik Temelli } \\
\text { Yöntemler }\end{array}$ & $\begin{array}{c}\text { Başarı Testi } \\
\text { Yabancı Dilde Dinleme } \\
\text { Kaygısı Ölçeği }\end{array}$ \\
\hline
\end{tabular}

\section{Çalıșma Grubu}

Çalışma grubunu Şehit Üstat Rabbani Üniversitesinden amaçsal örnekleme yöntemlerinden ölçüt örnekleme tekniğiyle belirlenen Türk Dili ve Edebiyatı Öğretmenliği Bölümü B2 seviyesinde 61 öğrenci oluşturmaktadır. Amaçlı örnekleme yöntemi, birtakım ölçütleri içeren veya belirli özellikler içeren bir veya birden fazla özel durumlarda çalışılmak istenildiğinde (Büyüköztürk, Kılıç-Çakmak, Akgün, Karadeniz \& Demirel, 2010); zengin bilgi edinilebilecek ve detaylı araştırma yapılabilecek katılımcıların seçilmesi ve güvenilir sonuçlar elde edilmesi açısından önemlidir (Fraenkel, Wallen \& Hyun, 2012). Bu araştırmada çalışma grubu B2 seviyesinde Türkçe bilen öğrencilerden seçildiği için ölçüt örnekleme tekniğine başvurulmuştur.

Çalışmada deney ve kontrol gruplarının belirlenmesi amacıyla araştırmacı tarafından geliştirilen "Katılımcı Tanıma Formu" aracıllğıyla öğrencilerin sahip oldukları teknolojik donanım durumları tespit edilmiştir. Katılımeı tanıma formuyla 71 öğrenciden veri toplanmıştır. Ulaşılan veriler doğrultusunda 10 öğrencinin akıllı telefon ve internet bağlantısına sahip olmadığı belirlenmiştir. Bu 10 öğrenci çalışma grubunun dışında tutulmuştur. Kalan 61 öğrenciye ise "Türkçe Yeterlik Sınavı Dinleme Bölümü” ön test olarak uygulanmıştır. Ayrıca grupların oluşturulmasında çalışmanın sonuçlarına etkisi olabileceği düşünülen bazı değişkenler (Türkiye'de bulunup bulunmama, daha önce e-dinleti dinleyip dinlememe, yakın çevresinde Türkçe konuşan biri/lerinin olup olmadığı) açısından grupların eşleştirilmesi sağlanmıştır. Bu doğrultuda çalışma sonuçlarına etkisi olabileceği düşünülen değişkenler dikkate alınarak ve dinlediğini anlama başarısı ön test puanlarına göre 30 kişi deney 31 kişi kontrol grubunda olacak biçimde birbirine denk iki grup oluşturulmaya çalışılmıştır.

Oluşturulan grupların dinlediğini anlama başarısı ön test puanlarına göre normal dağılım gösterip göstermediğini belirlemek amacıyla normallik testi yapılmıştır. Örneklem sayısı 50'nin üzerinde olduğundan ilk olarak Kolmogorov-Smirnov testi 
yapılmıştır. Test sonuçlarına göre $(\mathrm{p}=0.2)$ başarı puanlarının normal dağılım gösterdiği belirlenmiştir. Deney grubu basıklık (-,793), çarpıklık (,203); kontrol grubu basıklık $(-, 907)$, çarpıklık $(, 243)$ değerlerinin $\mp 1$ aralığında olduğu görülmüştür. Ayrıca Levene testi $p=0.69$ olduğundan grup varyanslarının da homojen olduğu belirlenmiştir. Ayrıca histogram grafikleri incelenmiş olup grupların dinlediğini anlama başarısı açısından normal dağılım sergiledikleri görülmüştür. Deney ve kontrol grupları dinlediğini anlama başarısı ön test puanlarını karşılaştırmak amacıyla bağımsız gruplar t-testi yapılmıştır. Deney ve kontrol grubu dinlediğini anlama başarısı ön test puanları arasında anlamlı bir farklılığın olmadığ 1 tespit edilmiştir $\left(\mathrm{t}_{(59)}\right.$ $=-.054, \mathrm{p}>.05)$. Deney ve kontrol gruplarına ait demografik veriler Tablo 2' de verilmiştir:

Tablo 2.

Çalışma Grubu Demografik Veriler

\begin{tabular}{llrrr} 
& & Deney & Kontrol & Toplam \\
\hline \multirow{2}{*}{ Cinsiyet } & Kız & 16 & 21 & 37 \\
& Erkek & 14 & 10 & 24 \\
\hline \multirow{3}{*}{ Yaş } & $19-21$ & 11 & 19 & 30 \\
& $22-23$ & 17 & 11 & 28 \\
& $24-25$ & 2 & 1 & 3 \\
\hline
\end{tabular}

Tablo 2 incelendiğinde, deney grubunun 16 kız 14 erkek, kontrol grubunun ise 21 k1z 10 erkek öğrenciden oluştuğu görülmektedir. Çalışma grubunun yaş durumları incelendiğinde deney grubunda 22-23 yaş, kontrol grubunda ise 19-21 yaş öğrencilerin fazla olduğu görülmektedir.

\section{Veri Toplama Araçları}

\section{Türkçe yeterlik sınavı (dinleme bölümü)}

Çalışmada geçerlik ve güvenirlik çalışmaları Yunus Emre Enstitüsü Sınav Merkezi tarafından hazırlanan Türkçe Yeterlik Sınavı (dinleme bölümü) nicel veri toplama aracı olarak kullanılmıştır. Türkçe Yeterlik Sınavının "Dinleme" bölümü altı metinden ve otuz sorudan oluşmaktadır. Metinlere ait sorular doğru yanlış (üç), eşleştirme (dört) ve çoktan seçmeli (yirmi üç) soru tiplerinden oluşmaktadır. Sınavdan alınabilecek en yüksek puan 25'tir. Sinav ayrıca Afganistan'daki bir üniversitede Türkoloji bölümünde öğrenim görmekte olan B2 seviyesinde 64 öğrenciye uygulanmıştır. Sınav sonrası elde edilen veriler üzerinde alfa $(\alpha)$ modeli kullanılarak güvenirlik analizi yapılmıştır. Toplam 64 öğrencinin katıldığı dinlediğini anlama başarı testinin sonuçları üzerinde yapılan güvenirlik analizi sonucunda $\alpha=.757$ olarak hesaplanmıştır. Güvenirlik katsayısının .70’ten yüksek oluşu testin güvenilir olduğunu göstermektedir (Field, 2009).

\section{Yabancı dilde dinleme kaygısı ölçeği}

Araştırmada öğrencilerin dinlemeye yönelik kaygıları hakkında bilgi edinmek amacıyla Polat ve Erişti (2018) tarafindan geliştirilen "Yabancı Dilde Dinleme Kaygısı Ölçeği” kullanılmıştır. Ölçek 5'li likert tipinde olup toplam 18 madde 
içermektedir. 12 madde (1. 2. 3. 4. 5. 6. 7. 8. 9. 10. 11. ve 12. maddeler) "bireysel ve çevresel etmenler", 3 madde (13. 14. ve 15. maddeler) "dinleme kaynağının kontrolü" ve 3 madde (16. 17. ve 18. maddeler) "dinleme etkinliklerine yüklenen anlam" olmak üzere üç faktörlüdür, Bu maddeler "Bana hiç uygun değil, bana uygun değil, bana biraz uygun, bana oldukça uygun, bana tamamen uygun" olmak üzere beş kategoride ölçeklendirilmiştir. Ölçekte yer alan kategoriler "Bana tamamen uygun" kategorisinden başlanarak sırayla 5, 4, 3, 2, 1 olarak puanlanmıştır. Afganistan'daki Türkoloji bölümlerinde öğrenim görmekte olan 101 öğrenciden toplanan verilerle elde edilen güvenirlik analizleri sonucunda ölçeğin Cronbach Alpha güvenirlik katsayısı 0,71 olarak tespit edilmiştir.

\section{Katılımcı tanıma formu}

Bağımlı değişken üzerinde etkisi olabilecek katılımcı özelliklerini belirlemek amacıyla oluşturulan bu form ilgili alan yazın doğrultusunda hazırlanmıştır. İlgili formun içerik ve dil kontrollerinin yapılması amacıyla iki alan uzmanı tarafından incelenmesi sağlanmıştır. Alan uzmanlarının görüş ve önerileri doğrultusunda ilgili düzenlemeler yapılmıştır. Form aracılığıyla ulaşılan bulguların araştırma sorularını cevaplayabilecek nitelikte olmasına dikkat edilmiştir.

\section{Verilerin Analizi}

Veri analizinde bağımlı gruplar t-Testi ve MANOVA testleri kullanılmıştır. Bu testlerin uygulanabilmesi için sağlanması gereken ön şartlar incelenmiştir. T- testine yönelik normal dağılım, varyansların homojenliği, aykırı değer gibi varsayımlar sağlanmıştır. Ayrıca MANOVA testinde sağlanması gereken örneklem büyüklüğü, varyans-kovaryans matrislerinin homojenliği, eş doğrusallık ve teklilik, normallik ve aykırı değerler, doğrusallık, çok değişkenli normal dağılım varsayımları da sağlanmıştır. Testlere ilişkin varsayımların sağlandığı belirlenmiştir ve araştırma sorularını cevaplamak amacıyla bağımlı gruplar $t$ testi ve MANOVA testi yapılması uygun görülmüştür.

\section{Deneysel İşlem}

Deney ve kontrol grupları belirlenip dinlediğini anlama başarısı ve yabancı dilde dinleme kaygısı ölçeğiyle ön test verileri alındıktan sonra deney grubuna haftada bir kez olmak kaydıyla altı hafta boyunca e-dinletiler gönderilmiştir. Deney grubundaki öğrenciler cep telefonları, bilgisayar ve tabletleri aracıllı̆ıyla indirdikleri e-dinletileri altı hafta boyunca istedikleri yerde istedikleri kadar dinlemişlerdir. Kontrol grubundaki öğrenciler ise geleneksel yöntemle derslerine devam etmiştir. Altı hafta sonunda deney ve kontrol grubuna dinlediğini anlama başarı testi ve yabancı dilde dinleme kaygısı ölçeği son test olarak uygulanmıştır.

\section{Çıkar Çatışması ve Etik Bildirim}

Makalenin yazarı olarak, bu makalede yazarlar arasında çıkar çatışması bulunmadığını, bilimsel ve etik kurallara uyulduğunu beyan ederim. 


\section{Bulgular}

\section{Deney Grubuna Ait Uygulama Öncesi ve Sonrası Dinlediğini Anlama Başarısı ve Yabancı Dilde Dinleme Kaygısı Ön Test-Son Test Farkı}

Deney grubuna ait ön test-son test dinlediğini anlama başarısı ve yabancı dilde dinleme kaygı düzeyi puanlarının karşılaştırılması için bağımlı gruplar t-Testi yapılmıştır. Ulaşılan t-Testi sonuçları Tablo 3 'te sunulmuştur.

Tablo 3.

Deney Grubuna Ait Dinlediğini Anlama Başarısı ve Yabancı Dilde Dinleme Kaygl Puanlarına İlişkin Ön Test-Son Test Sonuçları

\begin{tabular}{lcccccc}
\hline Deney Grubu & N & Ortalama(X) & SS & df & t & p \\
\hline $\begin{array}{l}\text { Dinlediğini Anlama Başarısı } \\
\text { Ön Test }\end{array}$ & 30 & 9.8 & 2.73 & 29 & & \\
$\begin{array}{l}\text { Dinlediğini Anlama Başarısı } \\
\text { Son Test }\end{array}$ & 30 & 13.47 & 2.67 & 29 & -6.971 & .000 \\
\hline $\begin{array}{l}\text { Yabancı Dilde Dinleme Kaygısı } \\
\text { On Test }\end{array}$ & 30 & 56.37 & 15.19 & 29 & & \\
$\begin{array}{l}\text { Yabancı Dilde Dinleme Kaygısı } \\
\text { Son Test }\end{array}$ & 30 & 41.80 & 9.37 & 29 & 4.438 & .000 \\
\hline
\end{tabular}

Tablo 3'te görüldüğü gibi deney grubunda dinlediğini anlama başarısına ait son test puanları ( $\overline{\mathrm{X}}=13.47, \mathrm{SS}=2.67)$ ön test puanlarından $(\overline{\mathrm{X}}=9.8, \mathrm{SS}=2.73)$ yüksektir. Yabancı dilde dinleme kaygısı son test puanları $(\overline{\mathrm{X}}=41.80, \mathrm{SS}=9.37)$ yabancı dilde dinleme kaygısı ön test puanlarından $(\overline{\mathrm{X}}=56.37, \mathrm{SS}=15.19)$ daha düşüktür. Hem dinlediğini anlama başarısı $(\mathrm{t}(29)=-6.971, \mathrm{p}<.05)$ hem de yabancı dilde dinleme kaygısı $\left(\mathrm{t}_{(29)}=4.438, \mathrm{p}<.05\right)$ ön test-son test puanları arasında anlamlı farklılık olduğu tespit edilmiştir.

\section{Kontrol Grubuna Ait Dinlediğini Anlama Başarısı ve Yabancı Dilde Dinleme Kaygısı Ön Test-Son Test Farkı}

Kontrol grubu için de ön test-son test dinlediğini anlama başarısı ve yabancı dilde dinleme kaygısı puanlarının karşılaştırılması için bağımlı gruplar t-Testi yapılmıştır. Ulaşılan t-Testi sonuçları Tablo 4'te sunulmuştur.

Tablo 4.

Kontrol Grubuna Ait Dinlediğini Anlama Başarısı ve Yabancı Dilde Dinleme Kaygı Puanlarına İlişkin Ön Test-Son Test Sonuçlart

\begin{tabular}{|c|c|c|c|c|c|c|}
\hline Kontrol Grubu & $\mathrm{N}$ & Ortalama $(X)$ & SS & df & $\mathrm{t}$ & $\mathrm{p}$ \\
\hline $\begin{array}{l}\text { Dinlediğini Anlama Başarısı } \\
\text { Ön Test }\end{array}$ & 31 & 9.84 & 2.81 & 30 & & \\
\hline $\begin{array}{l}\text { Dinlediğini Anlama Başarısı } \\
\text { Son Test }\end{array}$ & 31 & 10.77 & 3.90 & 30 & -1.430 & .163 \\
\hline $\begin{array}{l}\text { Yabancı Dilde Dinleme } \\
\text { Kaygisı Ön Test }\end{array}$ & 31 & 57.29 & 14.12 & 30 & & \\
\hline $\begin{array}{l}\text { Yabanc1 Dilde Dinleme } \\
\text { Kaygis1 Son Test }\end{array}$ & 31 & 52.23 & 10.04 & 30 & 2.126 & .042 \\
\hline
\end{tabular}


Tablo 4'te görüldüğü gibi kontrol grubunda dinlediğini anlama başarısına ait son test puanları $(\overline{\mathrm{X}}=10.77, \mathrm{SS}=3.90)$ ve yabancı dilde dinleme kaygısı son test puanları $(\overline{\mathrm{X}}=52.23, \mathrm{SS}=14.12)$, dinlediğini anlama başarısı ön test puanları $(\overline{\mathrm{X}}=9.84, \mathrm{SS}=2.81)$ ve yabancı dilde dinleme kaygısı ön test puanlarından $(\bar{X}=57.29, \mathrm{SS}=14.12)$ daha yüksektir. Kontrol grubunda dinlediğini anlama başarısı ön test-son test puanları arasında anlamlı bir farklılığın olmadığı tespit edilmiştir $\left(\mathrm{t}{ }_{(30)}=-1.430, \mathrm{p}>.05\right)$. Yabancı dilde dinleme kaygısı ön test-son test puanları arasında ise anlamlı farklılık tespit edilmiştir $\left(\mathrm{t}_{(30)}=2.126, \mathrm{p}<.05\right)$.

\section{Deney ve Kontrol Gruplarının Dinlediğini Anlama Başarısı ve Yabancı Dilde Dinleme Kaygısı Son Test Puanlarının Karşılaştırılması}

Bağımlı değişken açısından grupların anlamlı bir şekilde farklılaşıp farklılaşmadığını tespit edebilmek amacıyla MANOVA analizi yapılmıştır. Analize ait bulgular Tablo 5 'te yer almaktadir.

Tablo 5.

Dinlediğini Anlama Başarısı ve Yabancı Dilde Dinleme Kaygı Düzeyine İlişkin Manova Bulgulart

\begin{tabular}{lcccc}
\hline & Wilks Lambda $(\Lambda)$ & $\mathrm{F}$ & $\mathrm{p}$ & $\eta 2$ \\
\hline Kesen & .017 & 1633.36 & .000 & .983 \\
Grup & .738 & 10.271 & .000 & .262 \\
\hline
\end{tabular}

Tablo 5 incelendiğinde deney grubu ve kontrol grubu arasında anlamlı bir farklılık olduğu görülmektedir (Wilk's Lambda $(\Lambda)=.738, \mathrm{~F}_{(1,59)}=10.271, \mathrm{p}<.05$ ). Wilks Lambda değeri anlamlı çıktığından gruplar arasındaki farklılık detaylı incelenmiştir. Ulaşılan bulgular Tablo 6'da yer almaktadır.

Tablo 6.

Gruplara Göre Dinlediğini Anlama Başarısı ve Kaygı Düzeyindeki Farklılıklar

\begin{tabular}{clcccccc}
\hline $\begin{array}{c}\text { Bağımsız } \\
\text { Değişken }\end{array}$ & \multicolumn{1}{c}{$\begin{array}{c}\text { Bağımlı } \\
\text { Değişken }\end{array}$} & $\begin{array}{c}\text { Kareler } \\
\text { Toplamı }\end{array}$ & $\begin{array}{c}\text { Ortalama } \\
\text { Karesi }\end{array}$ & SD & F & p & $\begin{array}{c}\text { Etakare } \\
(\eta 2)\end{array}$ \\
\hline $\begin{array}{c}\text { Düzeltilmiş } \\
\text { Model }\end{array}$ & $\begin{array}{l}\text { Dinlediğini Anlama } \\
\text { Başarısı }\end{array}$ & 110.52 & 110.52 & 3 & 9.837 & .003 & .143 \\
& $\begin{array}{l}\text { Yabancı Dilde } \\
\text { Dinleme Kaygısı }\end{array}$ & 1657.19 & 1657.19 & 3 & 17.55 & .000 & .229 \\
& & & & & & \\
Kesen & $\begin{array}{l}\text { Dinlediğini Anlama } \\
\text { Başarısı }\end{array}$ & 8958.78 & 8958.77 & 1 & 797.4 & .000 & .9231 \\
& $\begin{array}{l}\text { Yabancı Dilde } \\
\text { Dinleme Kaygısı }\end{array}$ & 134786.7 & 134786.8 & 1 & 1427 & .000 & .960 \\
Grup & $\begin{array}{l}\text { Dinlediğini Anlama } \\
\text { Başarısı }\end{array}$ & 110.52 & 110.52 & 1 & 9.837 & .003 & .143 \\
& $\begin{array}{l}\text { Yabancı Dilde } \\
\text { Dinleme Kaygısı }\end{array}$ & 1657.19 & 1657.19 & 1 & 17.55 & .000 & .229 \\
\hline & & & & & & \\
\hline
\end{tabular}


E-dinleti temelli dinleme etkinliklerinin dinlediğini anlama başarısı üzerindeki etkisi incelendiğinde grup değişkeni açısından anlamlı farklılık saptanmıştır $\left(F_{(1,59)}=9.837, p<.05, \eta 2=.14\right)$. Ayrıca etki değerine göre grup değişkeni, bağımlı değişken varyansının \%14'ünü açıklamaktadır. Bu doğrultuda deney grubundaki öğrencilerin ( $\mathrm{X}=13.47, \mathrm{SS}=2.67)$, kontrol grubundaki öğrencilere göre $(\mathrm{X}=10.77$, $\mathrm{SS}=3.90$ ) dinlediğini anlama başarısı puan ortalamalarının istatistiksel olarak anlamlı düzeyde daha yüksek olduğu ortaya çıkmıştır. Bir diğer bağımlı değişken olan kaygı puanlarında da anlamlı farklılık gözlenmiştir. Kaygı puanlarında grup değişkeni açısından anlamlı farklılık saptanmıştır $\left(\mathrm{F}_{(1,59)}=17.55, \mathrm{p}<.05, \eta 2=.23\right)$. Ayrıca etki değerine göre grup değişkeni, bağımlı değişken varyansının \%23'ünü açıklamaktadır. $\mathrm{Bu}$ doğrultuda deney grubundaki öğrencilerin $(\mathrm{X}=41.80, \mathrm{SS}=9.37)$, kontrol grubundaki öğrencilere göre $(\mathrm{X}=52.23, \mathrm{SS}=10.04)$ kayg1 puanlarındaki ortalama farklılıklarının istatistiksel olarak anlamlı düzeyde daha düşük olduğu ortaya çıkmıştır.

\section{Tartışma}

Bu çalışmada, ilgili alan yazın dikkate alınarak geliştirilen e-dinletilerin, yabancı dil olarak Türkçe öğrenen B2 seviye öğrencilerin dinlediğini anlama başarısına ve dinleme kaygısına etkisinin belirlenmesi amaçlanmıştır. Araştırma soruları doğrultuda elde edilen bulgular alan yazınla ilişkilendirilerek tartışılmış ve yorumlanmıştır.

\section{E-dinletilerin Öğrencilerin Dinlediğini Anlama Başarısına Etkisi}

Çalışmada e-dinleti temelli dinleme uygulamalarının öğrencilerin dinlediğini anlama başarısına etkisini incelemek amacıyla yapılan MANOVA testinden elde edilen veriler e-dinletilerin dinlediğini anlama başarısı üzerinde anlamlı bir fark yarattığını ortaya koymaktadır. Etki değerine bakıldığında bağımlı değişkenlerdeki varyansın \%14'ünün grup değişkeni tarafından açıklandığı tespit edilmiştir. Sonuç olarak edinleti uygulamaları kullanılarak yürütülen deney grubundaki öğrencilerin dinlediğini anlama başarı puanlarının kontrol grubundaki öğrencilerden daha yüksek olduğu ortaya çıkmıştır.

E-dinletilerin genellikle mobil teknolojiler aracılığıyla kullanılmasının zaman ve mekân esnekliği yarattığı ve öğrencilerin kendi öğrenme hızlarına uygun bir şekilde öğrenmelerine imkân sağladığı için (Abdulrahman vd., 2018) dinlediğini anlama başarısını pozitif yönde etkilemiş olabileceği düşünülmektedir. Ayrıca bu özelliklerin öğrenci konsantrasyonunu canlı tuttuğundan öğrencilerin dinlemeden sıkılmalarını engellediği söylenebilir (Hammersley \& Atkinson, 1995). Kısıtlı sözcük dağarcığ1, sınıf içi etkinliklerde dinleme metni tekrarlarının öğretmen kontrolünde olması, dinleyicinin konuşmacının konuşma hızına müdahale edememesi ve metinde geçen kültürel bilginin farkında olamama dinlediğini anlama başarısını negatif etkileyen unsurlardır (Brown, 1995; Carroll, 1977; Dilidüzgün, 2013; Underwood, 1989). 
Uygulamada kullanılan e-dinletilerde "ileri al, geri al, durdur, tekrar dinle, ses tonu ve konuşmacı hızı" gibi ayarların kullanıcı kontrolünde olması geleneksel dinleme etkinliklerinde görülen konuşmacının konuşma hızına müdahale edememe, dinleme metni tekrarlarının öğretmen merkezli olması gibi sınırlılıkları gidermiş ve dinlediğini anlama başarısına pozitif etki etmiş olabilir. Nitekim e-dinletilerin dinlediğini anlama başarısı üzerindeki etkisini inceleyen deneysel çalışmalar (Abdulrahman vd., 2018; Ahmed, 2016; Kavaliauskiene, 2008; NamazianDost vd., 2017; Qasim \& Al Fadda, 2013; Rahimi \& Soleymani, 2015; Shiri, 2014) bu çalı̧̧madan elde edilen bulguları desteklemektedir.

\section{E-dinletilerin Öğrencilerin Dinleme Kaygısına Etkisi}

Çalışma sonucunda ulaşılan bulgulara göre deney grubundaki öğrencilerin dinleme kaygısı ölçeğinden aldıkları puanlar kontrol grubundaki öğrencilerin puanlarından düşüktür. Çalışmada e-dinleti temelli dinleme uygulamalarının öğrencilerin dinleme kaygısına etkisini incelemek amacıyla yapılan MANOVA testi aracılı̆̆ıla ulaşılan verilere göre iki grupta da kaygı düzeyinde azalma olmasına rağmen deney grubunda daha fazla azalma olduğu gözlenmiştir. Bu durum, deney grubunda e-dinleti uygulamaları neticesinde dinlediğini anlama başarısının artması öğrencilerin kendilerine olan güvenlerini artırarak yabanc1 dilde dinleme kayg1 seviyelerini düşürdüğü şeklinde yorumlanabilir. Alan yazında bazı çalışmalar (Chan \& Lee, 2005; Evans, 2008; Rahimi \& Soleymani, 2015) bu sonuçla paralellik göstermektedir.

Oxford (1993), metinlerde yer alan bütün kelimeleri anlama çabasının da öğrencilerde kaygıya neden olduğunu ifade etmektedir. Çalışmada kullanılan edinletilerin metinde geçen bazı kelimeleri açıklama kısmında ele alan bir tasarıma sahip olmasının da bu bağlamda kaygıyı düşürmede etkili olduğu söylenebilir. Aynı zamanda bazı sınıf içi dinleme etkinliklerinde öğretmen (Price, 1991; Young, 1990) ve akran uyaranları (Young, 1990) öğrenciler için endişe verici, huzursuzluk yaratıcı faktörler olarak değerlendirilmektedir. E-dinletilerin esnek kullanım alanı yaratması; sınıftaki dinleme etkinliklerinin dışında gerçek yaşam durumlarında pratik yapmaya imkân tanıması; kişilerin kendi öğrenme hızlarına adapte edilebilmesi öğrencilerde stres ve korku durumlarının azalmasını sağlamış olabilir. Bu nedenle e-dinleti temelli uygulamalar öğrencilerde kaygı seviyelerinin düşmesini sağlamış olabilir.

Çalışma bulguları incelendiğinde hem deney hem kontrol grubunda dinleme kaygısı puanları açısından anlamlı farklılık gözlenmektedir. Ancak dinlediğini anlama başarısı açısından sadece deney grubunda anlamlı farklılık gözlenmiştir. Bu durum Türkçe öğrenme süreci ilerledikçe öğrencilerin dilin yapısı, dil becerileri ve kelime dağarcığı vb. artmasıyla süreç içerisinde kaygının doğal olarak azaldığı şeklinde yorumlanabilir. Her iki grupta da kaygı puanlarının düşmesine rağmen deney grubunda kontrol grubuna göre dinlediğini anlama başarısı daha yüksektir. Bu durum, 
deney grubunda dinlediğini anlama başarısını e-dinletilerin etkilediği düşüncesini güçlendirmektedir.

\section{Sonuç}

MANOVA testi bulguları incelendiğinde dinlediğini anlama başarısı açısından deney grubundaki öğrencilerin kontrol grubundaki öğrencilerden daha başarılı olduğu tespit edilmiştir. Bu sonuç e-dinleti temelli etkinliklerin dinleme eğitiminde kullanılabilecek dinlediğini anlama başarısını artıran etkili bir uygulama olabileceğini göstermektedir.

Kaygı düzeyinin belirlenmesi amacıyla yapılan bağımlı gruplar t-Testi sonuçlarında hem deney hem de kontrol grubunda kaygı düzeyinde anlamlı bir farklılık gözlenmiştir. Bu sonuç her iki yöntemde de öğrencilerin zamanla Türkçe öğrenme kaygılarında düşüş olduğunu göstermektedir. Bu durum Türkçe öğrenimine maruz kaldıkça doğal olarak kaygının azalabildiğine işaret etmektedir. Ancak her iki grubun son test kaygı puanlarının karşılaştırıldığı MANOVA testi sonuçlarında deney grubundaki öğrencilerin kaygı düzeylerinin kontrol grubundaki öğrencilerin kayg1 düzeylerinden daha düşük olduğu tespit edilmiştir. Deney grubu lehine gözlenen bu sonucun istatistiki açıdan anlamlı sayılabilecek düzeyde olduğu görülmüştür.

\section{Öneriler}

1. Bu çalışmada e-dinletilerin dinlediğini anlama başarısına ve dinleme kaygısına etkisi incelenmiştir. E-dinletilerin diğer dil becerilerine veya kelime öğrenmeye etkisi incelenebilir.

2. Bu çalışma yurt dişında Türkoloji bölümü öğrencileri ile yürütülmüştür. Çalışmada elde edilen bulguların genellenebilirliğinin sağlanması amacıyla farklı ve daha büyük gruplarla tekrarlanabilir.

3. Bu çalışma yabancı dil olarak Türkçe öğrenen B2 düzeyindeki öğrencilerle gerçekleştirilmiştir. B1, C1 düzeyindeki öğrencilerle de çalışılabilir.

4. Bu çalışmada kullanılan e-dinletiler sadece ses içermektedir. Yeni çalışmalarda farklı e-dinleti türleri (resimlerle genişletilmiş veya videolarla desteklenmiş) kullanılabilir.

5. Bu çalışmada e-dinletiler destekleyici materyal olarak kullanılmıştır. E-dinletiler sınıf içi dinleme müfredatı ya da dinleme etkinlikleriyle bütünleştirilebilir.

\section{Çıkar Çatışması ve Etik Bildirimi}

Yazarlar, aralarında çıkar çatışması bulunmadığını ve çalışmaya eşit oranda katkı sunduklarını beyan etmiştir. Yazarlar, tüm etik kurallara uyduklarını bildirmiştir. 


\section{Kaynakça}

Abdous, M., Camarena, M., \& Facer, B. (2009). MALL technology: Use of academic podcasting in the foreign language classroom. RECALL Journal, 21(1), 76-95.

Abdulrahman, T.R., Basalama, N., \& Widodo, M.R. (2018). The impact of podcasts on EFL students' listening comprehension. International Journal of Language Education, 8(6), 23 33. https://doi.org/10.26858/ijole.v2i2.5878

Açık, F. (2008, 27 - 28 Mart). Türkiye'de yabancılara Türkçe öğretilirken karşılaşılan sorunlar ve çözüm önerileri. Uluslararası Türkçe Eğitimi ve Öğretimi Sempozyumu Bildirisi, Doğu Akdeniz Üniversitesi Eğitim Fakültesi Türkçe Eğitimi Bölümü, Lefkoşa.

Ahmed, F. (2016). Using podcasts to improve listening comprehension in the Arabic classrooms.

http://www.isna.net/wpcontent/uploads/2016/10/using_podcasts_to_improve_listening_co mprehensionfatimamaghdaoui.pdf adresinden alındı.

Al Fadda, H., \& Al Qasim, N. (2013). From Call to Mall: The effectiveness of podcast on EFL higher education students' listening comprehension. English Language Teaching, 6(9), 3041. https://doi.org/10.5539/elt.v6n9p30

Altunkaya, H. (2017). Yabancı dil olarak Türkçe öğrenenlerin dinleme ve okuma kaygıları. Education Sciences, 12(3), 107-121. https://doi.org/10.12739/NWSA.2017.12.3.1C0672

Bingöl, A.M., Celik, B., Yildiz, N., \& Tuğrul, M.C. (2014). Listening comprehension difficulties encountered by students in second language learning class. Journal of Educational and Instructional Studies in the World, 4(4), 1-6.

Blaisdell, M. (2006). Academic mp3's. Is it time yet? Campus Technology. http://www.campus-technology.com/print.asp?ID1/418001 adresinden alınd1.

Brown, G. (1995). Dimensions of difficulty in listening comprehension. In D. Mendelsohn and J, Rubin (Eds.), A guide for the teaching of second language listening. (p. 59-73). Dominie Press.

Büyükikiz, K.K. (2014). Türkçeyi yabancı dil olarak öğrenen C1 düzeyindeki öğrencilerin dinleme becerisine ilişkin görüşleri. Gaziantep University Journal of Social Sciences, 13(3), 793-805.

Büyüköztürk, Ş., Çakmak, E.K., Akgün, Ö.E., Karadeniz, Ş., \& Demirel, F. (2010). Bilimsel araştırma yöntemleri (5. Baskı). Pegem Yayıncılık.

Candaş-Karababa, Z. (2009). Yabancı dil olarak Türkçenin öğretimi ve karşıllaşılan sorunlar. Ankara Üniversitesi Ĕ̈itim Bilimleri Dergisi, 42(2), 265-277.

Carroll, J.B. (1977). On learning from being told. In M. C. Wittrock (Ed.), Learning and instruction (2nd ed., pp. 496-512). McCutchan.

Chan, A., \& Lee, M. (2005) An mp3 a day keeps the worries away - exploring the use of podcasting to address preconceptions and alleviate pre-class anxiety amongst undergraduate information technology students. Student Experience Conference, Charles Sturt University. http://www.csu.edu.au/division/studserv/sec /papers/chan.pdf adresinden alındi.

Chan, W. M., Chen, I. R., \& Dopel, M. (2011). Podcasting in foreign language learning: insights for podcast design from a developmental research project. Worldcall: Global Perspectives on Computer-Assisted Language Learning, 1, 19-37.

Chan, W-M., Chi, S-W., Chin, K-N., \& Lin, C-Y. (2011). Students' perceptions of and attitudes towards podcast-based learning: a comparison of two language podcast projects. Electronic Journal of Foreign Language Teaching. 8, 312-335.

Chester, A., Buntine, A., Hammond, K., \& Atkinson, L. (2011). Podcasting in education: student attitudes, behavior and self- efficacy. Educational Technology \& Society. 14(2), 236-247. 
Clark, D., \& Walsh, S. (2005). iPod-learning. Epic White Paper. http:// www.epic.co.uk/content/resources/white_papers/iPod.htm adresinden alındı.

Dilidüzgün, Ş. (2013). Dinleme eğitimi. Durmuş ve Okur (Ed.), Yabancılara Türkçe öğretimi el kitabı içinde (s. 259-276). Grafiker Yayınları.

Evans, C. (2008). The effectiveness of m-learning in the form of podcast revision lectures in higher education. Computers \& Education, 50(2), 491-498.

Field, J. (2013). Cognitive validity. In L. Taylor \& A. Geranpayeh (Eds.), Examining listening (pp. 77-151). Cambridge University Press.

Field, A. (2009). Discovering statistics using SPSS. Sage Publications.

Fraenkel, J.R., Wallen, N.E., \& Hyun, H.H. (2012). How to design and evaluate research in education. McGraw-Hill Humanities/Social Sciences/Languages.

Graham, S., \& Santos, D. (2015). Strategies for second language listening: Current scenarios and improved pedagogy. Springer.

Güneş, F. (2007). Türkçe ögrretimi ve zihinsel yapılandırma. Nobel Yayınları.

Halat, S. (2015). Yabancı dil olarak Türkçe ögrenenlerin dinleme becerisine yönelik kaygı düzeylerinin incelenmesi.(Tez No. 419392) [Yüksek lisans tezi, Gazi Üniversitesi-Ankara]. Yükseköğretim Kurulu Başkanlığı Tez Merkezi.

Hammersley, M., \& Atkinson, P. (1995). Insider accounts: listening and asking questions. Ethnography: Principles in Practice, 2, 124-156.

Hamouda, A. (2013). An investigation of listening comprehension problems encountered by Saudi students in the EFL listening classroom. International Journal of Academic Research in Progressive Education and Development, 2(2), 113-155.

Kaldırım, A., \& Degeç, H. (2017). Türkçeyi yabancı dil olarak öğrenen öğrencilerin dinleme esnasında karşılaştıkları sorunlar. Eğitim Bilimleri Araştırma Dergisi,7(1), 19-36.

Kaplan-Leiserson, E. (2005). Trend: podcasting in academic and corporate learning. Learning Circuits, 5(6), 398-401. http://www.learningcircuits.org/2005/jun2005/0506_trends adresinden alınd.

Kavaliauskienè, G. (2008). Podcasting: a tool for improving listening skills. Teaching English with Technology, 8(4). http://cejsh.icm.edu.pl/cejsh/element/bwmeta1.element.desklightaa648d8c-e935-4f9f-b987-3107a34a61b3 adresinden alınd1.

Krashen, S. (1982). Principles and practice in second language acquisition. Pergamon Press.

Lazzari, M. (2009). Creative use of podcasting in higher education and its effect on competitive agency. Computers \& Education, 52(1), 27-34.

Lund, R.J. (1991). A comparison of second language listening and reading comprehension. The Modern Language Journal, 75(2), 196-204. https://doi.org/10.1111/j.15404781.1991.tb05350.x adresinden alınd1.

Maden, S., \& İșcan, A. (2011). Yabancı dil olarak Türkçe öğretimi amaç ve sorunlar (Hindistan Örneği). Karadeniz Sosyal Bilimler Dergisi, 3(5), 23 - 37.

McBride, K. (2009). Podcasts and second language learning: promoting listening comprehension and intercultural competence. In Abraham and Williams (Eds.), Electronic Discourse in Language Learning and Language Teaching, s. 153-168. John Benjamins.

McCombs, S., \& Liu, Y.( 2007). The efficacy of podcasting technology in instructional delivery. International Journal of Technology in Teaching and Learning, 3(2), 123- 134.

McGarr, O. (2009). A review of podcasting in higher education: its influence on the traditional lecture. Australasian Journal of Educational Technology, 25(3), 309-321

McMillan, J.H., \& Schumacher, S. (2010). Research in education: evidence-based inquiry, MyEducationLab Series. Pearson.

Meng, P. (2005). Podcasting \& Vodcasting: a white paper, definitions, discussions \& implications. University of Missouri IAT Services. http://edmarketing. 
apple.com/adcinstitute/wp-content/Missouri_Podcasting_White_Paper.pdf adresinden alınd.

Menzies, D. (2005). Duke University iPod first-year experience final evaluation report. Duke Center for Instructional Technology. http://cit.duke.edu/pdf/iPod_ initiative_04_05.pdf adresinden alınd.

Merchant, G. (2012). Mobile practices in everyday life: popular digital technologies and schooling revisited. British Journal of Educational Technology, 43(5), 770-782.

Nation, I.S., \& Newton, J. (2008). Teaching ESL/EFL listening and speaking. Routledge.

NamazianDost, I., Bohloulzadeh, G., \& Rahmatollahi, R. (2017). The effects of using podcast on listening comprehension among Iranian pre-intermediate EFL learners. International Journal of Applied Linguistics and English Literature, 6(6), 57-70. https://doi.org/10.7575/aiac.ijalel.v.6n.6p.57

O'Bryan, A., \& Hegelheimer, V. (2007). Integrating CALL into the classroom: the role of podcasting in an ESL listening strategies course. RECALL Journal, 19(2), 162-180.

Oxford, R.L. (1993). Research update on teaching L2 listening. System, 21(2), 205-211. https://doi.org/10.1016/0346-251X(93)90042-F

Polat, M. \& Erişti, B. (2018). Yabancı dilde dinleme kaygısı ölçeğinin geliştirilmesi. Educational Sciences, 13 (11). 1113-1138. http://dx.doi.org/10.7827/TurkishStudies.13438

Price, M. L. (1991). The subjective experiences of foreign language anxiety: interviews with highly anxious students. In E.K. Horwitz \& D.J. Young (Eds.). Language anxiety: from theory and research to classroom implications (pp. 101-108). Englewood Cliffs. NJ: Prentice Hall.

Rahimi, M., \& Soleymani, E. (2015). The impact of mobile learning on listening anxiety and listening comprehension. English Language Teaching, 8(10), 152-161. https://doi.org/10.5539/elt.v8n10p152

Royal, K. \& Von Koss, N. (2008). Using podcasting in the foreign language classroom. Into faculty and staff publications. https://scholarcommons.usf.edu/cgi/viewcontent.cgi?article=1010\&context=into facpub adresinden alınd.

Scarcella, R.C., \& Oxford, R.L. (1992). The tapestry of language learning: The individual in the communicative classroom. Heinle \& Heinle.

Shiri, S. (2015). The application of podcasting as a motivational strategy to Iranian EFL learners of English: a view toward listening comprehension. Advances in Language and Literary Studies, 6(3), 155-165. http://journals.aiac.org.au/index.php/alls/article/view/1522 adresinden alındi.

Sloan, S. (2005). Podcasting: an exciting new technology for higher education. Paper presented at CATS 2005: March 25, 2005. http://www.edupodder.com/ conferences/index.html adresinden alınd.

Stanley, G. (2006). Podcasting: audio on the internet comes of age. TESL-EJ, 9(4), 1-7. http://www-writing.berkeley.edu/TESL-EJ/ej36/int.pdf adresinden alındı.

Tabak, G., \& Göçer, A. (2014). Dinleme becerisine yönelik alternatif ölçme ve değerlendirme araçları. Bartın Üniversitesi Ë̆itim Fakültesi Dergisi, 3(2), 250-272.

Taşer, S. (2000). Konuşma ĕgitimi. Papirus Yayınları.

Underwood, M. (1989). Teaching listening. Longman.

Vandergrift, L. (2007). Recent developments in second and foreign language listening comprehension research. Language Teaching, 40(3), 191-210. https://doi.org/10.1017/S0261444807004338

Vandergrift, L., \& Goh, C.C.M. (2012). Teaching and learning second language listening: Metacognition in action. New York: Routledge.

Yılmaz, F. \& Babacan, G. (2015). Yabancı dil olarak Türkçe öğretiminde podcast kullanımı. 
International Periodical for the Languages, Literature and History of Turkish or Turkic 3(10), 1153-1170. http://dx.doi.org/10.7827/TurkishStudies.7837

Young, D.J. (1990). An investigation of students' perspectives on anxiety and speaking. Foreign Language Annals, 23(6), 539-553. https://doi.org/10.1111/j.19449720.1990.tb00424.x

Young, D.J. (1992). Language anxiety from the foreign language specialist's perspective: interviews with Krashen, Omaggio Hadley, Terrell, and Rardin. Foreign Language Annals, 25(2), 157-172. https://doi.org/10.1111/j.1944-9720.1992.tb00524.x

Wang, R., Wiesemes, R., \& Gibbons, C. (2012). Developing digital fluency through ubiquitous mobile devices: findings from a small-scale study. Computers \& Education, 58(1), 570 578. https://doi.org/10.1016/j.compedu.2011.04.013

\section{Extended Abstract}

Podcasting has ben considered as an innovative technology in language learning which offers more flexibility and portability of language materials. Podcast is a series of video and digital audio broadcast that could be downloaded and played on mobile devices. As supplementary materials, podcasts help students pay attention on its content and learn listening using bottom up and top down strategies all together. According to Sloan (2005), podcasting is an innovative way of broadcasting through the Internet and can be used for transferring audio content automatically to mobile phones. Moreover scholars have offered some reasons for supporting language learning classrooms via podcasts (Blaisdell, 2006; Clark \& Walsh, 2005; Meng, 2005, Sloan, 2005). They include that 1) podcasting provide pedagogic advantages when used as a complementary materials 2) Listening to podcasts can faciliate learning by providing comprehensible input 3) Podcast technology can makes learning easier, faster and attractive to the learners 4) Podcasts is possible anytime and anywhere. Students can save their time by downloading and listening podcasts at their own convenience.

Specifically in teaching listening comprehension, podcast technology used as primary source. Listening is an important skill that contributes to the internalization of language rules and faciliates the emergence of other language skills (Vandergrift, 2007). Listening comprehension is a complex, active and conscious action which listeners involved to analyze, interpret and constructing meaning. Listening has been reported to be a difficult skill due to the features like pauses, hesitants, false starts and intonatioal factors which limiting listeners comprehension success. Listeners' affective side seems to be most important factors that can influence the processing of information takes place. One of such traits is listening anxiety. According to Dilidüzgün (2003: 259), its difficult to understand responses full of discourse markers, even at normal speed, in a daily conversation that has different features than written language. Is such cases, it is possible to increase anxiety and stress fort he listener, who has not only understand what the speaker says but also give appropriate answers 
to what has been said (Vandergrift \& Goh, 2012: 4). Therefore determining the variables that play roles in the development of listening skills is an important subject in the field of second/foreign language teaching. Foreign language listening anxiety is one of the individual difference that is defined as "feelings of uneasiness, apprehension, tension or fear caused by the actions and different stimuli required by the manner of fulfillment of the skill before and during the listening process by individuals who are learning a foreign language or who are using the language that they have learned" (Polat \& Erişti, 2018).

The advantages of using podcast in language learning - specifally to assist students in listening comprehension have been researched, and the results show increase in students listening comprehension (Abdulrahman, Basalama \& Widodo, 2018; Al Fadda \& Al Qasim, 2013; NamazianDost, Bohloulzadeh \& Rahmatollahi, 2017; Rahimi \& Soleymani, 2015; Shiri, 2015). In the field of teaching Turkish as a foreign language, only one study could be found on podcasts. Y1lmaz ve Babacan (2015), in their studies, they developed podcasts to improve listening comprehension skills. In the study, they developed Turkish teaching materials according to themes in Common European Framework of Rreferences for Languages. Within the framework of the determined themes, six podcasts at A1 and A2 levels were designed by considering certain goals. In our literature, there is not any study examining the effect of podcasts on listening comprehension in the field of teaching Turkish as a foreign language.

In this study, the effect of podcasts on listening comprehension and listening anxiety of students who learn Turkish as a foreign language are examined. The study group of the study consists of 61 students at the B2 level who learn Turkish as a foreign language in Afghanistan. In the study, quasi-experimental design with pretestposttest control group was used. Supplementary podcasts were sent to the experimental group once a week for six weeks. The students in the control group continiued their lessons with traditional methods. "Turkish Proficiency Test" (part of listening) prepared by Yunus Emre Institute", "Foreign Language Listening Anxiety Scale" prepared by Polat and Erişti (2018), "Participant Identification Form” were used as data collection tools.

MANOVA test findings were examined, it was determined that the students in the experimental group were more successful than the students in the control group in terms of listening comprehension. This result shows that podcasts can be effective for developing students' listening comprehension. Dependent groups t-Test findings were examined to determine the level of foreign language listening anxiety, a significant difference was observed in the anxiety level of both the experimental and control groups. This result shows that students' foreign language listening anxiety level over time. This indicates that listening anxiety can naturally decrease as one improve 
his/her language proficiency. However, foreign language anxiety post-test scores of both group compared, MANOVA test results show that the listening anxiety levels of students in the experimental group were lover than the control group. This result, which was observed in favor of the experimental group, was found statistically significant. 